\title{
Atmospheric dispersion modelling with AERMOD for comparative impact assessment of different pollutant emission sources in an Alpine valley
}

\author{
E. Tomasi ${ }^{1,2}$, G. Antonacci ${ }^{3}$, L. Giovannini ${ }^{1,2}$, D. Zardi ${ }^{1,2} \&$ \\ M. Ragazzi ${ }^{1}$ \\ ${ }^{1}$ Department of Civil, Environmental and Mechanical Engineering, \\ University of Trento, Italy \\ ${ }^{2}$ National Consortium of Universities for Atmospheric and Hydrospheric \\ Physics (CINFAI), Rome, Italy \\ ${ }^{3}$ CISMA - Centro di Ingegneria e Sviluppo Modelli per l'Ambiente, \\ Bolzano, Italy
}

\begin{abstract}
High-resolution simulations are performed with the AERMOD dispersion model to assess the impact on air quality in the area surrounding the town of Vipiteno, in the Alps, from the main pollutant sources: the Brenner motorway, the town of Vipiteno, three major industrial plants and a big parking lot. The combination of terrain complexity and specific emission sources makes the air pollution load particularly critical for such a valley environment. AERMOD is run with a spatial resolution of $25 \mathrm{~m}$ and fed with specific meteorological data and emission factors, modulated according to hourly and seasonal emission patterns. The resulting annual means of $\mathrm{NO}_{2}$ and $\mathrm{PM}_{10}$ concentration are validated against measurements from a local air quality station and then compared with the limits set by legal provisions. Finally, the contributions of single sources are analysed, highlighting their relative relevance to the pollution load of the area.

Keywords: atmospheric dispersion modelling, AERMOD, complex terrain, atmospheric emission, idling vehicles.
\end{abstract}




\section{Introduction}

Air quality assessment over complex terrain is a delicate issue, especially when many different sources of pollutants act simultaneously. In this context, air quality modelling is a crucial tool to evaluate the spatial distribution of the overall pollutant concentration. In particular, the AERMOD model (from the AMS/US EPA, [1]) suits the need for applications at local scales, over complex terrain [2]. Nevertheless, great attention must also be paid to the meteorological and emission rate input data fed to the model, which significantly affect simulation results. In general, meteorological input data can be obtained from a reliable weather station located within the area of interest, or from simulations with a meteorological numerical model (e.g. Kesarkara et al. [3]). On the other hand, emission rate data are usually difficult to find and their uncertainty is usually high, varying significantly among different sources. The best practices for the estimation of emission rates from diffuse sources are reported in the European Environment Agency (EEA) guidelines [4], which were used to develop the regional Italian INEMAR emission inventory [5]. Considering the emissions from linear sources, such as road networks, a reference method is the COPERT model [6], while no standard approach exists in literature concerning the calculation of idling vehicle emissions. However, some examples are found in Rahman et al. [7] and Shancita et al. [8].

\section{Study area}

The present study focuses on the area surrounding Vipiteno, a small town in the North Eastern Italian Alps, close to the Austrian border. This area is particularly interesting for the interaction between a complex geomorphological configuration and several relevant pollution sources. Vipiteno, indeed, is located in a basin at $950 \mathrm{~m}$ above mean sea level in the Isarco Valley, which runs from north to south, at its connection with two lateral valleys, the Ridanna Valley and the Vizze Valley, on its western and eastern sides respectively. The main pollutant source in this area is the motorway axis (A22) leading to the Brenner pass and running along the Isarco Valley. Besides the air pollution load caused by this major source, the emissions from domestic, manufacturing and industrial settlements as well as from secondary traffic are also relevant. The present study also takes into account the emissions produced by a big parking lot which might be relevant due to its dimensions and location. Figure 1 shows the area of Vipiteno and the location of the main pollution sources taken into account in the present work. The weather and air quality stations, providing meteorological and concentration data used to run the simulation and to validate model results, respectively, are also shown.

\section{Model set-up}

In the present study the AERMOD [1] model is used to evaluate the impact on air quality of different emission sources in terms of $\mathrm{NO}_{x}$ and $\mathrm{PM}_{10}$. AERMOD is an 


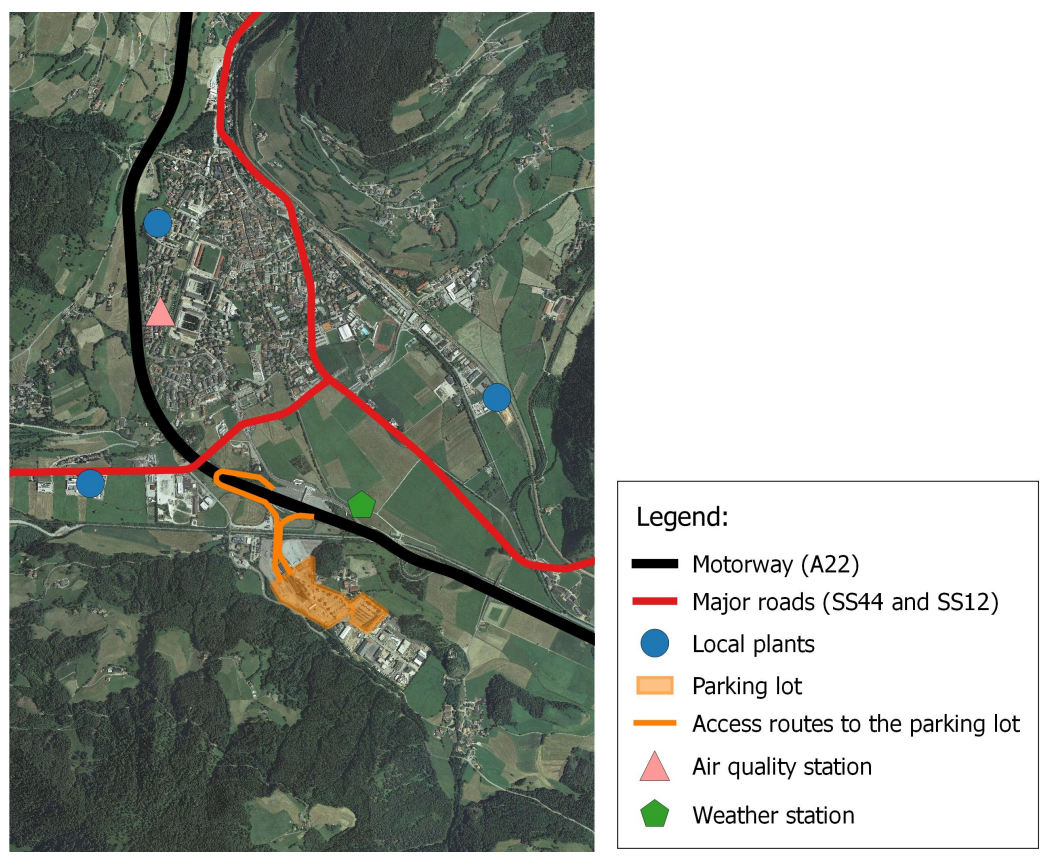

Figure 1: The area of Vipiteno with the main pollution sources and the meteorological and air quality stations considered in the present work (background aerial photo from the Autonomous Province of Bolzano 2011).

atmospheric dispersion modelling system composed of a steady-state dispersion solver (AERMOD) and two preprocessors (AERMET and AERMAP), which elaborate terrain and meteorological data to produce suitable input data for AERMOD.

The present work aims at evaluating pollutant concentrations at a local scale in order to get a fine overview on their spatial distribution: therefore, AERMOD was run on a domain of $15 \mathrm{~km}^{2}$ with a $25 \mathrm{~m}$ horizontally spaced grid. The input data describing orography and land cover must be coherent with these settings: accordingly, a $25 \mathrm{~m}$ digital terrain model (DTM) was provided and a land use map was produced, by reclassifying a $30 \mathrm{~m}$ Corine Land Cover map with the American NLCD standard classes, in order to match the software prerequisites.

Particular attention was also paid to the quality of meteorological and emission input data, as described in detail in the following sections.

\subsection{Meteorological data}

AERMOD can process two different types of meteorological data, namely ground based measurements and soundings. In the present work both types of data were fed to the model. 
The reference weather station chosen to run the AERMOD simulation is representative for the meteorological conditions of the area, as its data are scarcely affected by local effects. It is operated by the local weather service and has been working since 1999: data were validated and compared with observations from other meteorological stations within the area. After the validation process, the data recorded in 2012 were chosen for the AERMOD simulation, considering the consistency, the continuity and the age of the data.

Information passed to the model includes global insolation, pressure, temperature, wind speed and direction and relative humidity. All the variables are measured at $10 \mathrm{~m}$ above ground level, with a $10 \mathrm{~min}$ time resolution (except for the temperature, recorded each hour), and were fed to the model as hourly averages.

Due to the lack of vertical soundings close to the area of interest, near ground measurements taken at different elevations were used to produce 2-level pseudovertical soundings. The two stations used to this scope are Ladurns and Anticima Cima Libera, respectively located at 1960 and 3399 m above mean sea level. These meteorological stations provided information on the vertical profile of temperature and wind direction and speed.

\subsection{Emission sources}

In the present work, four major pollutant emission sources are taken into account, namely: the town of Vipiteno, the main road network, the major local industries and a parking lot, offering park spaces for up to 260 trucks and 50 cars. Each of these sources was analysed in detail in order to properly evaluate its influence on the overall pollutant concentration.

\subsubsection{Town of Vipiteno}

Pollutant emissions from the town of Vipiteno are primarily due to an intensive use of biomass for house heating (as no gas pipeline is available in the area) and then due to secondary traffic and small manufacturing industry. Emission rates for this source were evaluated starting from the Regional air pollutant emission inventory (INEMAR 2010 [5]): the inventory allows to calculate an average emission rate for each municipality, taking into account its specific activities and small scale industry (i.e. those not accounted for explicitly) and weighting them according to the number of people involved, the production volume, etc. The emission rate of Vipiteno was modelled as an annual mean value with temporal and spatial modulations. The latter was estimated from data coming from the 2011 population census, weighting the overall emission rate considering the population density of each census tract. On the other hand, the temporal modulation was evaluated considering the evolution in time of the main activities taken into account: the house heating and the secondary traffic. House heating is strongly characterized by seasonal and hourly cycles, while secondary traffic mainly varies per hourof-day and day-of-week. These different patterns were conveniently combined by weighting them on the basis of each activity contribution to the total amount of emission rate, according to the INEMAR emission inventory. 
Table 1: Annual mean emission rates and modulation for the town of Vipiteno INEMAR 2010.

\begin{tabular}{ccccc}
\hline & & $\mathrm{NO}_{x}$ & $\mathrm{PM}_{10}$ & Modulation \\
\hline \multirow{2}{*}{ Vipiteno } & {$\left[\mathrm{g} \mathrm{s}^{-1} \mathrm{inh}^{-1}\right]$} & $3.62 \mathrm{E}-5$ & $5.03 \mathrm{E}-5$ & seasonal, weekly, \\
& {$\left[\mathrm{g} \mathrm{s}^{-1} \mathrm{~m}^{-2}\right]$} & $1.42 \mathrm{E}-7$ & $1.97 \mathrm{E}-7$ & hourly \\
\hline
\end{tabular}

The town of Vipiteno was therefore modelled in AERMOD as a composition of 73 areas, treated as diffuse areal sources, emitting a mean value modulated in time: Table 1 reports all the features of the specific emission rate per inhabitant (as fed to AERMOD) and the corresponding areal mean value of emission for the whole domain.

\subsubsection{Main road network}

The major traffic routes crossing the domain are the Brenner motorway (A22) and two major roads (SS12 and SS44) which were modelled in the simulation as linear sources $25 \mathrm{~m}, 10 \mathrm{~m}$ and $8 \mathrm{~m}$ wide respectively. The emission rate for each axis was calculated by means of the EU standard COPERT model [6]: this procedure requires the number of transiting vehicles, the fleet composition and the mean vehicle speed as input data. For each of the above-mentioned roads, suitable data sets were obtained from data provided by different subjects: the company managing the Brenner motorway (the Autobrennero S.p.A.) for the motorway speed and transiting vehicles, the local institute for statistic (ASTAT) for the same quantities for the two major roads and the Italian federation of motorists (ACI) for the fleet composition of all the traffic routes. Table 2 summarises the mean speed and the mean daily number of transiting vehicles for the three roads. By combining the input data with the emission factor of each vehicle type, the total amount of emissions for both the motorway and the two major roads was obtained (see Table 3). This value was modulated in different ways for the A22 and the SS roads. The modulation introduced for the motorway, obtained from measured data, is day-of-week and hour-of-day dependent per each season, reproducing the intensification of traffic during daytime and the decrease of heavy traffic during the weekend. The proposed pattern for the two major roads, instead, is only hourof-day dependent, as there is no significant traffic variation on these routes during the weekends, and the transiting heavy vehicles are very few.

\subsubsection{Local plants}

Because of the local scale of the study, specific attention must be paid to three plants located within the domain, which may significantly contribute to the emissions in the atmosphere. These plants are the Vipiteno hospital, located inside the town center, the district heating plant and a small factory. In order to properly 
Table 2: Input data for the COPERT model.

\begin{tabular}{lcc}
\hline & Nr. of vehicles $[-]$ & Mean speed $\left[\mathrm{km} \mathrm{h}^{-1}\right]$ \\
\hline A22 & 29854 & 97 \\
SS12 & 7643 & 100 \\
SS44 & 13062 & 100 \\
\hline
\end{tabular}

Table 3: Emission rates and modulations for the main road network.

\begin{tabular}{lccc}
\hline & $\mathrm{NO}_{x}\left[\mathrm{~g} \mathrm{~s}^{-1} \mathrm{~m}^{-1}\right]$ & $\mathrm{PM}_{10}\left[\mathrm{~g} \mathrm{~s}^{-1} \mathrm{~m}^{-1}\right]$ & Modulation \\
\hline $\mathrm{A} 22$ & $7.45 \mathrm{E}-4$ & $1.57 \mathrm{E}-5$ & seasonal, weekly and hourly \\
$\mathrm{SS} 12$ & $1.61 \mathrm{E}-4$ & $3.04 \mathrm{E}-6$ & hourly \\
$\mathrm{SS} 44$ & $2.40 \mathrm{E}-4$ & $3.78 \mathrm{E}-6$ & hourly \\
\hline
\end{tabular}

Table 4: Emission rates and modulations for the local major plants.

\begin{tabular}{lccc}
\hline & $\mathrm{NO}_{x}\left[\mathrm{~g} \mathrm{~s}^{-1}\right]$ & $\mathrm{PM}_{10}\left[\mathrm{~g} \mathrm{~s}^{-1}\right]$ & Modulation \\
\hline Hospital & $1.18 \mathrm{E}-2$ & $2.38 \mathrm{E}-3$ & - \\
District heating & 1.91 & $2.22 \mathrm{E}-1$ & monthly \\
Small factory & $1.31 \mathrm{E}-1$ & $1.96 \mathrm{E}-2$ & weekly \\
\hline
\end{tabular}

simulate these sources in AERMOD, their release points of emission must be characterised with the height and diameter of the stack, and with the temperature and velocity of the emissions: these values were known for each plant. The annual mean emission rate of each point source is reported in the INEMAR 2010 inventory for both $\mathrm{NO}_{x}$ and $\mathrm{PM}_{10}$ and are shown in Table 4. These values were characterized with a suitable modulation which appeared to be weekly for the small factory, whose production cycle decreases during the weekends, and monthly for the district heating.

\subsubsection{Parking lot}

The parking lot taken into account is of particular interest for dimensions and position: it is indeed located not far from the town center and it can harbour up to 260 trucks and 50 cars. In addition, the company managing both the motorway and the parking lot had direct interest in analysing the emission rate of this facility, 
Table 5: Emission rates and modulations for the sources composing the parking lot.

\begin{tabular}{lcccc}
\hline & & $\mathrm{NO}_{x}$ & $\mathrm{PM}_{10}$ & Modulation \\
\hline Access routes & $\left.\left[\mathrm{g} \mathrm{s}^{-1} \mathrm{~m}^{-1}\right)\right]$ & $2.94 \mathrm{E}-5$ & $8.30 \mathrm{E}-7$ & seasonal and hourly \\
Admin. building & {$\left[\mathrm{g} \mathrm{s}^{-1}\right]$} & $4.28 \mathrm{E}-3$ & $4.97 \mathrm{E}-4$ & monthly \\
Parking lot & {$\left[\mathrm{g} \mathrm{s}^{-1} \mathrm{~m}^{-2}\right]$} & $1.32 \mathrm{E}-6$ & $1.32 \mathrm{E}-7$ & seasonal and hourly \\
\hline
\end{tabular}

in comparison with the other local sources. In the simulation this parking lot was modelled as the composition of three different types of sources: two linear sources, representing the access routes to the parking, a diffuse source, representing the parking area with standing or idling vehicles, and a point source, representing the administrative building within the area.

The emission rate for the linear source was calculated again using the COPERT model: the number of transiting vehicles was evaluated by means of a statistical analysis of the incoming and outgoing traffic to and from the parking (A22 S.p.A. - 2013), the fleet was considered to be composed only of heavy vehicles, and the mean speed was assumed to be $40 \mathrm{~km} \mathrm{~h}^{-1}$ which is the speed limit for these routes. The results of the COPERT analysis supplied an annual mean emission rate which was modulated with an hourly pattern per each season, calculated from the same traffic data.

On the other hand, the annual mean emission rate of the point source was obtained by considering the volume of the building and its heating system: this value was then modulated with a monthly pattern.

The evaluation of the emission rates for the diffuse source is instead much more delicate: few studies are available in literature which assess pollutant releases from idling vehicles [7-9]. In the present case the following hypotheses were made: all the idling vehicles are heavy-duty diesel vehicles (HDDV); all of them are standing with an auxiliary power unit (APU) in use; all the vehicles are always idling for the whole period of breaking in the parking lot, no matter the season of the year nor the hour of the day. The emission rate of each idling vehicle was determined according to standard values for this type of engine idling with the APU in use [7,10]: given the annual mean number of parked trucks, known from the available traffic data, the annual mean emission of the parking lot was easily calculated and modulated with data-based seasonal and hourly patterns. Table 5 summarises the emission rates of the three sources representing the parking.

\section{Results}

Simulation results are presented in terms of annual mean values of $\mathrm{NO}_{2}$ and $\mathrm{PM}_{10}$ concentrations. $\mathrm{NO}_{2}$ concentrations were obtained from AERMOD $\mathrm{NO}_{x}$ results 
by means of the Romberg approach, Romberg et al. [11]. Results from a regionalscale dispersion model run [12] were used as background values to be added to the simulated local concentrations: while $\mathrm{NO}_{2}$ background values were too low to be significant with respect to the local simulation uncertainty, and therefore neglected, background values from 3.9 to $7.3 \mu \mathrm{g} \mathrm{m}^{-3}$ were added to $\mathrm{PM}_{10}$ results.

In order to validate the simulations, numerical results were compared with observations from an air quality station (see Figure 1). A good agreement between model results, in the nearest cell to the station, and observations was found, in terms of annual mean values. In fact, the measured and simulated $\mathrm{NO}_{2}$ concentrations are 29.6 and $27.3 \mu \mathrm{g} \mathrm{m}^{-3}$, respectively, while the corresponding values for $\mathrm{PM}_{10}$ are 14.2 and $15.6 \mu \mathrm{g} \mathrm{m}^{-3}$. Moreover, a comparison between measured and simulated percentiles of $\mathrm{NO}_{2}$ daily-mean values was performed (Figure 2). As shown by the graph, the simulated curve fits very well the measured one, especially after the 55th percentile, but overestimates the number of very low concentrations and underestimates concentration maxima. This effect is probably due to the fact that emission rates were modelled as mean values with average temporal modulations: the model is therefore unable catch particular situations, such as for example traffic congestion on the motorway, which are connected with very intense pollution episodes.

The resulting distributions of pollutants are analysed and discussed considering the overall concentrations in the study area and the contribution from each single source. Figure 3 presents the concentrations of $\mathrm{NO}_{2}$ and $\mathrm{PM}_{10}$ within the domain, as the sum of the contributions of each source taken into account. $\mathrm{NO}_{2}$ results clearly show that the highest concentrations are registered along the motorway axis and that values above the legislative threshold $\left(40 \mu \mathrm{g} \mathrm{m}^{-3}\right)$ are reached very close to this major traffic route. On the other hand, $\mathrm{PM}_{10}$ maxima are far from the legislative limit of $40 \mu \mathrm{g} \mathrm{m}^{-3}$ on annual basis and their highest values are registered in the area surrounding the centre of Vipiteno, where most of the population lives, and again along the motorway.



Percentile

Figure 2: Measured and simulated percentile of $\mathrm{NO}_{2}$ concentrations. 

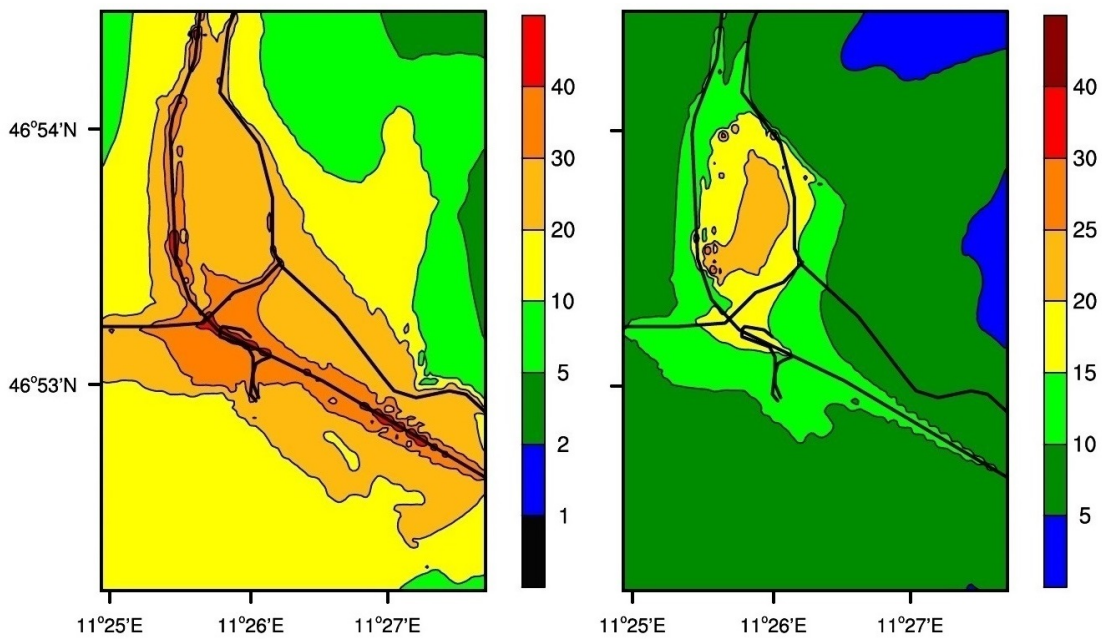

Figure 3: Annual mean value of $\mathrm{NO}_{2}$ (left) and $\mathrm{PM}_{10}$ (right) $\left[\mu \mathrm{g} \mathrm{m}^{-3}\right]-$ global concentrations.

Another interesting issue to analyse is the contribution of each single source to the overall pollutant concentrations: therefore, the relative contribution of each source to the total concentrations was calculated in each point of the domain and the resulting maps are presented in Figure 4. The top five panels, relative to $\mathrm{NO}_{2}$ concentrations, clearly demonstrate that the main source of this pollutant is the motorway, followed by the two main roads. It is therefore verified that the road network is accountable for almost $90 \%$ of the overall $\mathrm{NO}_{2}$ concentration in the domain: the most problematic area is the part of Vipiteno center closest to the motorway, due to its high population density. The bottom panels in Figure 4 show the relative contribution of each source in terms of $\mathrm{PM}_{10}$. The maps highlight that the main source of particulate matter is the town of Vipiteno with its intensive use of domestic biomass heating. The A22 motorway is also accountable for a relevant percentage of $\mathrm{PM}_{10}$ concentration, especially in its surrounding areas. In terms of both $\mathrm{NO}_{2}$ and $\mathrm{PM}_{10}$, the local plants and the parking lot have little impact on air quality and their influence on the overall concentration is spatially very limited, especially concerning annual mean values.

\section{Summary and conclusions}

The air quality of the area surrounding Vipiteno was assessed in terms of $\mathrm{NO}_{2}$ and $\mathrm{PM}_{10}$ concentrations by means of a numerical simulation with the AERMOD dispersion model. Four emission sources were taken into account and modelled in the simulation: the residential area of Vipiteno, the main road network, three local plants and a parking lot. The emission rate of each source was evaluated in detail 

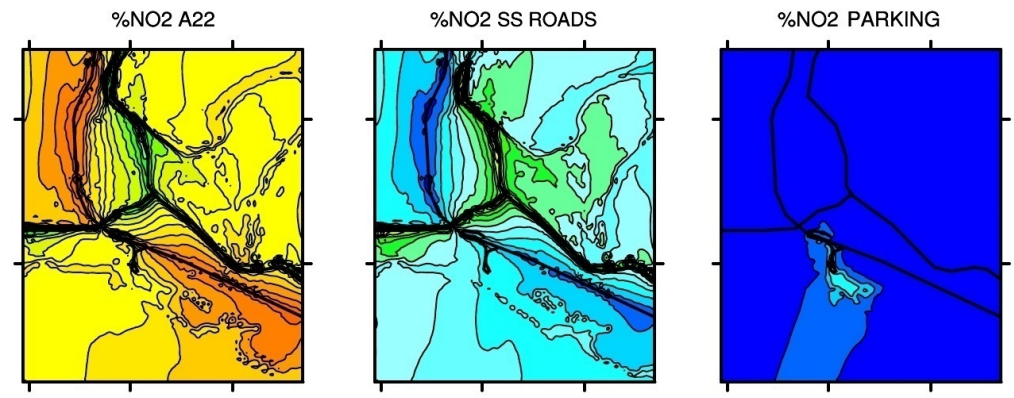

\%NO2 VIPITENO

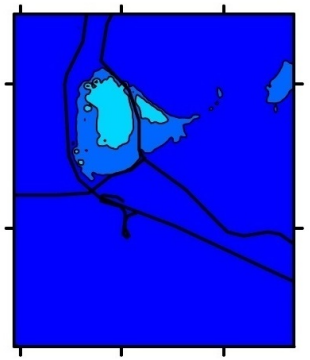

$\%$ NO2 PLANTS
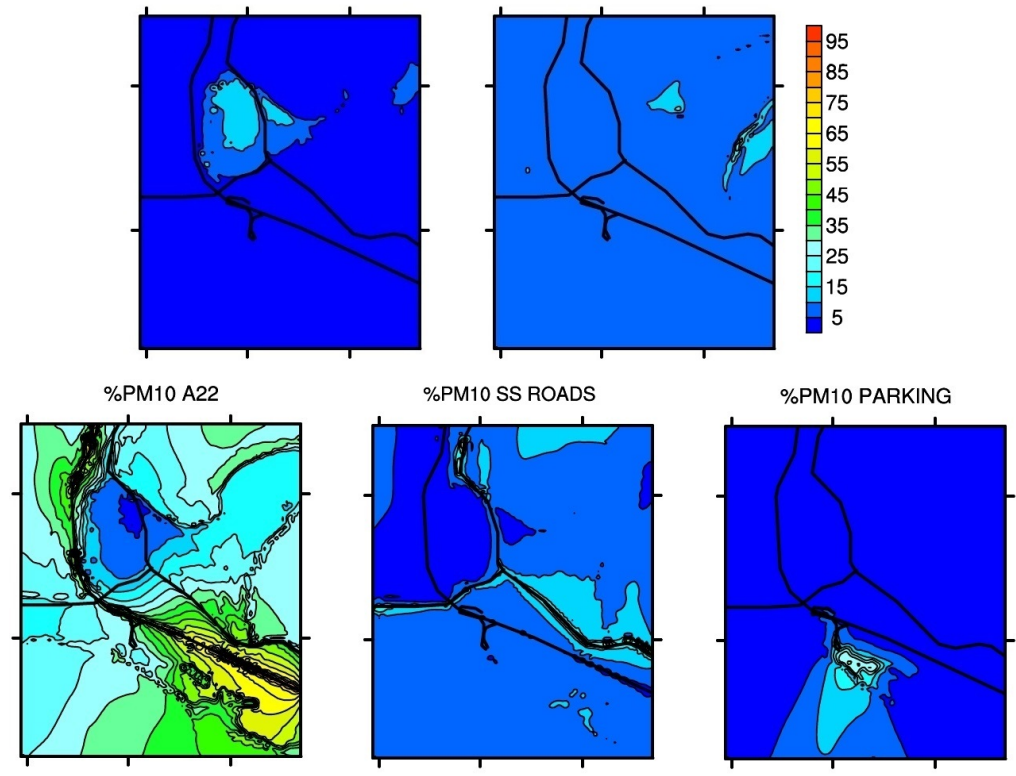

\%PM10 VIPITENO

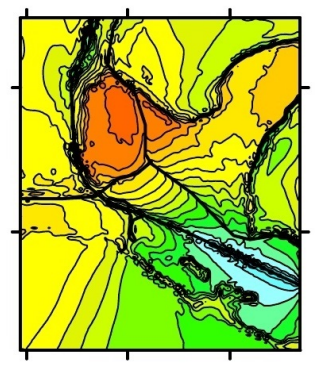

\%PM10 PLANTS

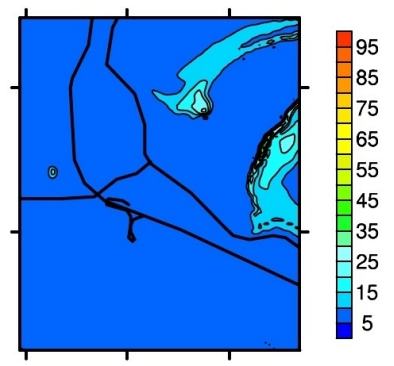

Figure 4: Percentage contribution of each source to the total amount of $\mathrm{NO}_{2}$ and $\mathrm{PM}_{10}$ concentrations. 
and reproduced within the model as an annual mean value modulated in time with hourly, monthly or seasonal patterns. The comparison of numerical results against observed values from an air quality station, located near the motorway, assessed the reliability of the performed simulation. The results of the study demonstrate that the principal source of $\mathrm{NO}_{2}$ is the main road network which causes the annual mean concentration to exceed the European legislative limit of $40 \mu \mathrm{g} \mathrm{m}^{-3}$ in the areas very close to the motorway. The main advantage of adopting a fine computational grid is that it allows a clear identification of concentration gradients near the emission points, and therefore an exact verification of where the limits are exceeded. On the other hand, the annual mean $\mathrm{PM}_{10}$ concentration is lower than the prescribed limit and the main source of this type of pollutant is the residential area of Vipiteno. The local plants and the parking lot have little impact on the overall pollution of the area.

\section{Acknowledgements}

The present study was funded by the Autobrennero S.p.A. which is also kindly acknowledged for providing vehicular traffic data along the Brenner motorway and within the Sadobre parking lot. The Meteorological Office of the Autonomous Province of Bolzano, the local and national institutes for statistic (ASTAT and ISTAT) and the Italian federation of motorists (ACI) are all kindly acknowledged for providing meteorological, vehicular traffic, population density and fleet composition data, respectively.

\section{References}

[1] A. J. Cimorelli, S. G. Perry, A. Venkatram, J. C. Weil, R. J. Paine, R. B. Wilson, R. F. Lee, W. D. Peters, R. W. Brode \& J. O. Paumier, AERMOD: description of model formulation. Technical report, U.S. Environmental Protection Agency - EPA, 2004.

[2] Holmes, N.S. \& Morawska, L., A review of dispersion modelling and its application to the dispersion of particles: an overview of different dispersion models available. Atmospheric Environment, 40, pp. 5902-5928, 2006.

[3] Kesarkara, A.P., Dalvia, M., Kaginalkara, A. \& Ojhab, A., Coupling of the Weather Research and Forecasting Model with AERMOD for pollutant dispersion modeling. A case study for PM10 dispersion over Pune, India. Atmospheric Environment, 41, pp. 1976-1988, 2006.

[4] EMEP/EEA air pollutant emission inventory guidebook 2013. Technical guidance to prepare national emission inventories. Technical report, European Environmental Agency - EEA, 2013.

[5] Inventario delle emissioni in atmosfera della Provincia Autonoma di Bolzano. Technical report, Autonomous Province of Bolzano, 2010. 
[6] D. Gkatzoflias, C. Kouridis, L. Ntziachristos \& Z. Samaras, COPERT IV Computer programme to calculate emissions from road transport. Technical report, European Environmental Agency - EEA, 2012.

[7] Rahman, S.M.A., Masjuki, H.H., Kalam, M.A., Abedin, M.J., Sanjid, A. \& Sajjad, H., Impact of idling on fuel consumption and exhaust emissions and available idle-reduction technologies for diesel vehicles - A review. Energy Conversion and Management, 74, pp. 171-182, 2013.

[8] Shancita, I., Masjuki, H.H., Kalam, M.A., Fattah, I.M.R., Rashed, M.M. \& Rashedul, H.K., A review on idling reduction strategies to improve fuel economy and reduce exhaust emissions of transport vehicles. Energy Conversion and Management, 88, pp. 794-807, 2014.

[9] Office of Transportation and Air Quality, Idling vehicle emissions for passenger cars, Light-duty trucks, and heavy-duty trucks. Technical report, U.S. Environmental Protection Agency - EPA, 2008.

[10] Frey, H.C. \& Kuo, P.Y., Real-world energy use and emission rates for idling long-haul trucks and selected Idle reduction technologies. Journal of the Air and Waste Management Association, 59(7), pp. 857-864, 2009.

[11] Romberg, E., Bösinger, R., Lohmeyer, A., Ruhnke, R. \& Röth, R., NO-NO2Umwandlung für die Anwendung bei Immissionsprognosen für Kfz-Abgase - Gefahrstoffe. Reinhaltung der Luft, 56, pp. 215-218, 1996.

[12] Valutazione della qualità dell' aria 2005-2015. Technical report, Environmental Protection Agency - Autonomous Province of Bolzano, 2010. 